\title{
Acquired vulvar lymphangioma: An enigma
}

\section{Radhika Varma}

\author{
Department of Dermatology Venereology and Leprosy, Government Medical College, Thrissur, India
}

Corresponding author: Dr. Radhika Varma, E-mail: drradhikavarma@gmail.com

A 44-year-old female developed multiple solid dusky-red and skin-colored labial papules and plaques with rough surfaces and warty excrescences (Fig. 1). The overlying skin was hyperpigmented, indurated, and rugose. The lesions had developed over a couple of years and were asymptomatic. There was no crusting or oozing. There was a long medical history of vulval lymphedema secondary to filariasis. An excisional biopsy of a papule showed papillated epidermal hyperplasia and focal parakeratosis. The papillary dermis showed a "Swisscheese"-like appearance secondary to lymphedema and superficial sciatic thin-walled vascular spaces with a proteinaceous fluid characteristic of lymphangiectasias (Fig. 2). The patient was treated with vulvectomy and has shown no sign of recurrence to date.

Lymphangioma circumscriptum, or acquired lymphangioma, is the most common form of cutaneous lymphangioma and may occur at any age [1]. Congenital lymphangiomas are hamartomatous malformations of lymphatic vessels, whereas acquired lymphangiomas arise due to acquired obstruction of lymph vessels following surgery, infection - such as erysipelas and tuberculosisor radiation treatment. The sites of predilection for acquired lymphangioma are the proximal extremities, trunk, axilla, and oral cavity, especially the tongue [2]. The female external genitalia are a very rare site for lymphangioma circumscriptum [1-3]. The differential diagnosis of lesions in the genitalia includes condylomata lata, genital warts, molluscum contagiosum, herpes zoster, seborrheic keratosis, and even leiomyoma [3].

In spite of the absence of a standard therapy for lymphangiomas, various modalities of treatment have been suggested, such as observation, surgical excision of the skin and subcutaneous tissues, surface ablation with laser (CO2, Er:YAG), sclerotherapy, and superficial radiotherapy. Intense pulse light and pulse dye laser may also be tried. Surgical excision is the treatment of

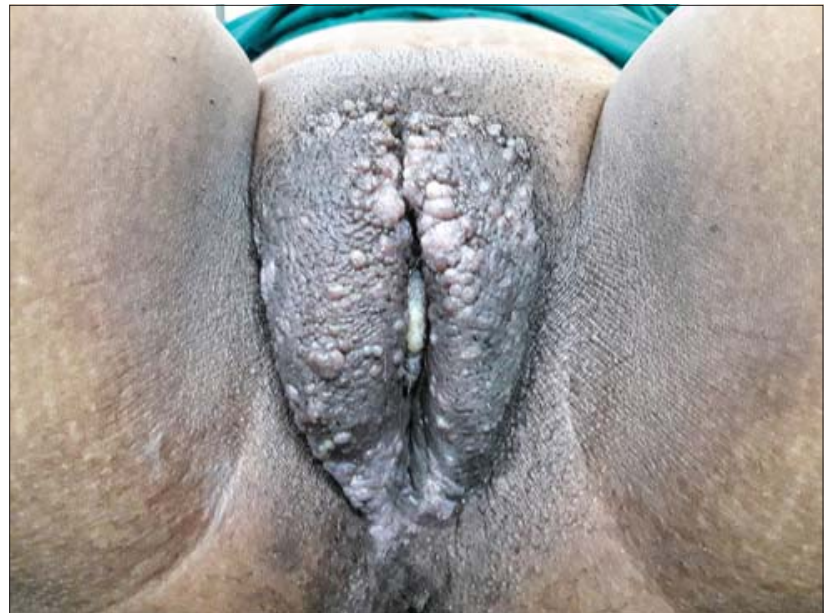

Figure1: Numerous sessile dusky-red and skin-colored warty papules and plaques in the vulva in a background of hyperpigmented and rugose skin.

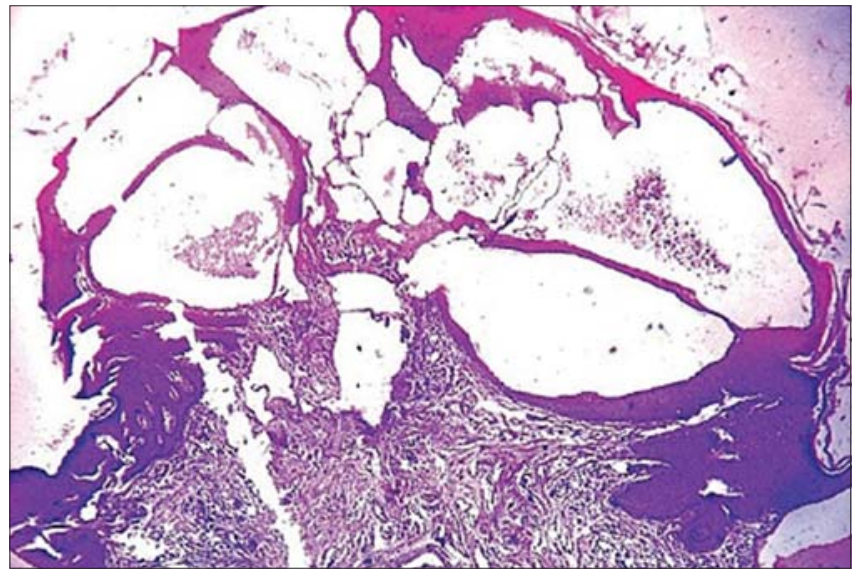

Figure 2:Acanthosis and hyperkeratosis of the epidermis along with numerous dilated lymphatic channels in the upper dermis containing proteinaceous eosinophilic material (H\&E, 100x).

choice with a high success rate for lesions confined to the superficial dermis $[1,3]$.

\section{Consent}

The examination of the patient was conducted according to the principles of the Declaration of Helsinki.

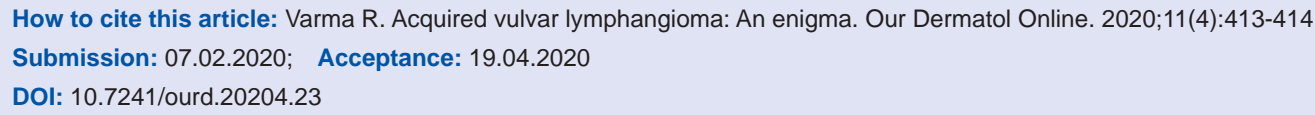




\section{www.odermatol.com}

The authors certify that they have obtained all appropriate patient consent forms, in which the patients gave their consent for images and other clinical information to be included in the journal. The patients understand that their names and initials will not be published and due effort will be made to conceal their identity, but that anonymity cannot be guaranteed.

\section{REFERENCES}

1. Fatani MI, Bitar M, Afif K A, Baltow B, Bagdadi S. Lymphangioma circumscriptum of the vulva mimicking genital wart: A case report. JSSDDS. 2013;17:29-31.
2. El Kadiri S, Chaoui R, Douhi Z, Elloudi S, Baybay H, Mernissi FZ. Lymphangioma circumscriptum of the vulva and Klippel-Trenaunay syndrome. Our Dermatol Online. 2020;11(e):e10.1-e10.2.

3. Mansouri S, Mai S, Ismaili N, Benzekri L, Hassam B. Acquired vulvar lymphangioma circumscriptum: a report of 3 cases. Our Dermatol Online. 2019;10:156-8.

Copyright by Radhika Varma. This is an open-access article distributed under the terms of the Creative Commons Attribution License, which permits unrestricted use, distribution, and reproduction in any medium, provided the original author and source are credited.

Source of Support: Nil, Conflict of Interest: None declared. 